\title{
IGBO THEORY OF KNOWLEDGE: THEORETICAL AND METHODOLOGICAL CONSIDERATIONS.
}

\author{
Albert O. M. Ogoko
}

\begin{abstract}
Ontological truth held by traditions in the history of human knowledge is that man irresistibly, desires to know. The Igbo is not precluded from treading this rational part. Contrarily, Eurocentric's as a mythology enunciates an I-other/we-they epistemic divide, serving an ideological project. White is rational black is not. This ideological space differentiation sought to foundation every other construct, in economics and politics, in the socio-culture and religion, and even in epistemology. It is argued that philosophical enterprise arises out of individual rational activities. Whatever is thought and discussed of any reality and sphere of human activity stems out of a particular epistemic matrix and paradigms, mental or ideological coloration of a people. It is not the case that every thought or rational enquiry amounts to a philosophy. Similarly cultural practices cannot be exhumed as philosophy. But given this moulding, the problems of relativism and commensurability not withstanding, we can talk of Igbo theory of knowledge as reflecting a perspective of this universal enterprise.
\end{abstract}

\section{Introduction}

Basic in the rationality debate about the existence of African philosophy, I will say, is an epistemological problem. Henry Oruka, in Four Trends in Current African Philosophy may have condemned African philosophy because this referent derives from a "body of thoughts and belief" produced by an "unique way of thinking." He is cautious in accepting the possibility of an erected African philosophy because its claim to an unique conceptual scheme radically divorces from the logical format of Western tradition: "It is assumed that there is a way of thinking or a conceptual frame work that is uniquely African and which is at the same time radically in European." ( D. Alwin, ed.,1) Besides, he thinks (or did think) that proffering an answer to the question what is African philosophy may be too early or perhaps the question is a nonsensical verbiage like 
what is African death? ( Sodipo, ed., 133). Now, beyond a decade, Professor Odera Oruka and others who shared this opinion must have shifted position. However, their reasons are not far fetched. African philosophical discourse is almost totally apologetic and for the greater part is determined by the nature of debates/arguments directed against the discipline. In most of our institutions, programmes of studies are not yet structured to reflect the true nature and need for an African philosophy. At best in most cases what is tenable is just introductory course work for a semester or two. In these instances there is the dearth of academic hands and near absence of textbooks on which to ground tutorials. It was against this background that Oruka H. Odera premised his argument,

To the extent that European philosophy is known to manifest critical and rigorous analysis, and logical explanations and synthesis, African philosophy is considered to be innocent of such characteristics. It is considered to be basically intuitive, mythical and counter or extra rationalistic (in, Diemer Alwin, 1)

Granted, philosophy is a universal human activity. Given also the difference of and relativity of our environment and cultural practices are we justified to ground our evaluation of Igbo (African) experience on European formula? It might be argued that knowledge is knowledge everywhere as metaphysics is metaphysics, and mathematics is. The same principle or law might be in application. But the manner of applying and explaining that reality, say a theorization might vary. The implication of the claims of Odera Oruka and his likes is that it takes up and amplifies Eurocentric discourse against the rationality of African people. This discourse is strongly countered by V.U. Mudimbe's The Invention of Africa, The Idea of Africa; D. Masolo's African philosophy in Search of an Identity; Cheik Anta Diop's African Origin of Greek Civilization; T.U. Nwala, S. Oladipo, N. Otakpor among others.

The Igbo seeks to know and to understand, to explain and to describe his /her experiences and grasps of realities. Such sifts are articulated as our world-view. From it a body of knowledge is constructed. It encapsulates the principles conditioning his responsecriteria. He or she must also explain an understanding of the 
exigencies of nature and articulate rationale as justification for a proffered theory. This theory has been battered in the mould of Western interpretations. Given the disjuncture of our historical experience, the reality of our ontological experiences is to be interpreted within that of the rich phenomenological gamut of cultural environment.

The obvious problematic here is not the possibility of the noetic experience. Rather it bothers now on nomenclature, whether or not one should be talking about Igbo theory/conception of knowledge, or simply Igbo epistemological/ metaphysical notions, etc. We have Chinese philosophy, Indian philosophy (Oriental), Western philosophy (Continental rationalism and Empiricism), German Idealism, Arab philosophy, etc on continental, regional and other levels. Each of these shares unique factors characteristic of a particular, political, social, economic culture, a given historical experience, social discourse and knowledge matrix. Each of these traditions evolved theories tending towards a common ontological truth of all reality. Various theories are made and on the basis of factual life experience these are re-evaluated and modified. We judge these various theories as commensurable, verisimilar, etc because each arrives at the same truth about reality from different vantage points.

\section{Philosophy as Worldview}

Philosophy is the search for ultimate reality. Philosophy is a universal activity and is strictly one if it is rational and critical, logical and systematic, non-suppositional, reflective, evaluative and synthetic, etc in method. Though universal philosophy is the domestication of a world-view. Every philosophizing arises out of a particular cultural mould, attitudinal climate, value system, epistemological matrix and conceptual scheme, ontological categorization, and so forth. Cultural practice is universal in so far as there are common categories around which every people and race conceive their thought, analyze, criticize and synthesize their views and perception of realities. Culture then reflects such traditions as the principles and justification of knowledge on the basis of the uniqueness of their historical and ontological experience. For instance there is the Newtonian synthesis of enlightenment and 
industrial revolution. On this cultural tradition, philosophy veered dangerously into mechanism. Examples are the philosophies of Baruch Spinoza, Leibniz, Rene Descartes, and Immanuel Kant among others. Again think of the way the social conditions created by political upheaval in consequence of the Enlightenment and industrial revolution in France and Britain inspired the (political) philosophies of John Locke, Thomas Hobbes, Jean Jacques Rousseau among others, and Machiavellian by the need for the Italian Prince consolidating and wielding absolute power; and the ultimate imperial rationalization of Hegel's idea in the History of world philosophy.

\section{Knowledge Matrix}

Peter du Preezin A Science of Mind, The quest for psychological Reality thinks that to understand a theory in terms of a knowledge matrix one ought to concern himself/herself with questions about the Social and intellectual contexts and content of theories. In the first place theories perform social functions and are socially conditioned. These functions are determined by social structures. The social matrix reflects the psychological attitudes, and habits of the people, their ideological make up, rhetoric and manoeuvres and intellectual discourses (4). If theories are socially conditioned how do we escape from relativism and determine the verity of our theory? We (i) "admit that different theories arise in different cultures and social structures" and (ii) still claim that these can be compared and evaluated. (6) But we encounter epistemic and judgmental relativism respectively.

A semiotic approach to culture, takes every culture to consist of as a system of signs. Hence it is information carrier. We do not see culture. But at each stage we can always point at some concrete material reality, which informs us of the thing in question about this culture. It is a kind of a phenomenology, and this always embodies a rationale, serving the pedagogical and elitist functions. The various elements of culture-language, marriage, custom, tradition, folklore, myths, festivals, arts and poetry, etc employ various materials in their actual practice. Some of these include clothing of different colours, food items-yam, cassava, and palm wine; specific objects, and animals: kola-nuts, chalk clay, egg, hides and skins, palm fronts, 
masks, implements of work, weapons of war and symbols of peace, specific kinds of trees' bark, roots or leaves, buildings, etc serve practical purposes, act as monuments and perform textual functions (12). How do the details of the text hang together into an episteme? The life of man (in the generic) with others of his kind in every moment of his existentiality is a dialectical one. He enters into a kind of dialectic with nature and with material things, which are purposeful creation of his rationality, his artifice and ontological quest, the basis of his sustenance and strivings. Every day, fresh questions are raised; the old answers are once more taken up and reexamined about this world, wicked or beautiful, Uwa nkea ruru aru, nke juputara na nsogbu, uwa oma, etc, about the nature of man, madu (Nma di) as repository of God's goodness, his follies, and wisdom, mode of perception, intellection, validation of truth, about politics, economics, history etc..

The primary objects of Igbo knowledge are God, Spirits, ancestors and material substances. God is an eternal rationality, infinite immaterial substance, and supreme in essence. He is allpowerful, hence being called the most Supreme Being, Chi-ukwu and consequently the creator and sustainer of all life, God is the only Being that creates ex nihilo, He is Chi n'eke. God is the first and final cause of all things. By a causal necessity all things determinately follow and are ordained. Freedom is complying with this determinism. Whatever was, is and will be is already ordered to be so.... Whatever we are, can attain or achieve must derive from God. We are efficient causal agents with distinctive destiny parcels. Since God is Supremely removed or distanced from mortal men, we reach him through other media ....Man also enters into dialectics with forces in nature. The world is saturated with the power of God. Man learns to harness it....Life is cyclic and nothing is unconnected. Every thing is related; one thing flowing into the other. The mechanistic dualism of the mind-body interaction postulated by Rene Descartes and others do not apply in Igbo metaphysical space.

At all times we discover we make appeal to the veracity of the senses, or the evidence of authority or the ontological finality of the intellect as the capacity for being, capax entis. Whatever he or she senses he or she thinks. Whatever he or she thinks in the abstract he or she tries to substantiate into the concrete. Trends in empiricism, 
idealism, pragmatism, materialism and rationalism can be delineated, though not easily due to what I consider a unique mathematical and logical operation. The rhythm in nature, the flow and interaction of beings reveal the principles by which beings are in dialectic. Ontologically, there are dialectical principles in things. The principles seek to explain the nature of individual things. It also explains how it relates to, how it is in harmony and or in conflict and the dialectical process involved. It is this reality that reason seeks to raise up as science. Science refers to the articulated body of knowledge resultant of the practice (noun), then as verb the manner of the procedure or method.

The Igbo is as empirical as he is rational. He employs his organs of sight, sound, taste, touch, and perceiving in interacting with his environment. To effectively explore and harness its promises and riches and to control its excesses the man strives to understand what he is dealing with. For Newton-Smith the scientific enterprise is made intelligible on the assumptions of realism. Realism is incompatible with the indeterminacy of translations as Quine would want us accept. To subscribe to indeterminacy Newton-Smith argues, implies that we cannot even make categorical statements about nature, reality and the world. If there is nothing to be said and expressed in words and in language then nothing can be claimed as true or otherwise falsified. The realist pictures the world as being more or les determinate and takes it to be possible to frame assertions, which express the state of the world. This is only possible if sentences have more or less determinate sense (181).

Thus, the scientific method has been described as a modification of common-sense realism. Correlations do exist between observable phenomena. Pre-scientific common-sense procedure entails the discovery of such correlations. The observed correlations bring about controlled circumstances in which to test conjecture. Repeated conjunctions of observable refine into the scientific method. From tests and hypothesis it finally evolves into inductively supported metaphysical principles and axioms. The Igbo world-view is rich in this. Within our social community, new angles, suggestions, options, and methods are tried and conceptual schemes and mode of categorization are improved. As regards judgmental relativism in connection with the comparability of different theories 
Preez asserts that it does not state that it is always possible, or that any theory can be compared with any other, but merely that in certain significant instances we can judge one theory to be better than another. Where we are not able to do this it is because theories are indistinguishably bad or because they totally work in different domains as a theory of magnetism and a theory of angels must (7). Cultures vary one from another that it is not always possible to compare them.

\section{The Question of Method}

He who desires an end must have a means to achieve it. Descartes in the Discourse on Method explains that method "consists entirely in the order and disposition of the objects towards which our mental vision must be directed."(xv) For Angeles, it is "the Systematic means which a philosopher uses to attain truth, or the procedure by which knowledge is obtained." (76) The question of method in Igbo theory of knowledge depends upon the material object of Igbo epistemology. In other words what forms the "content" so to speak of notice experience. These content materials are to be found enshrined and encapsulated in the material and immaterial aspects of our culture. This explains Igbo realities in an ocean world of realities. Rationality is brought to bear in articulating realities. And if a people also have a language, then there is a way of conceptualizing their experiences of reality. Given the nonavailability of texts in this area, we need to rely on the retrievability of the oral as preserved and encased in proverbs, idiomatic and figurative expressions (immaterial aspect of culture), as well as the visible material aspects of the practice, hence orality on text. There are certain statements that are monumentalized as traditions, as the words of our elders, which are always there and are open for the ever-ongoing dialectic, and discourses of our environment.

Such areas, though witnessing certain redefinitions are textual. In this vein, examination of language as a system of signs and symbols is important. A sign points to a thing or reality. Symbol stands for or takes the place of another thing. The words we employ in spoken and written communication express meanings and so point to a reality and stands for something else (Adler, ed., 730). Words as signs and symbols get the meanings they express from our ideas, 
thoughts, feelings and emotions, desires, etc. It is about our everyday interactions; politics, economics, morals, ideology, etc in the market place, in schools, and other social gathering. Such social engagements entail discourses, dialectics and transfer of meanings or displacement. The relation between metaphor, metonymy and myth is explained as set of cognitive manoeuvres for understanding the similarities, associations and essences of our social environment. We think metaphorically when we associate perceived similarities between things. We "look at one thing as though it were another, while remaining aware that it is not.

When we cease to be aware of a distinction, similarity becomes identity."( Preez, 79). Metonymy is a change of name. In Igbo agu (lion) is a name implying bravery. In this discourse we describe a thing by "some accompaniment or significant adjunct, instead of naming the thing itself." Okada as commercial motorcyclists imply swiftness. (80) .We search for new combinations, contiguities and associations in things. To think mythically is to attempt to "reduce the distance between discourse and reality." We create sacred language or discover a world of real or proper names. $(80,81)$ Certain expressions in Igbo such as okpokoro isi, isi aturu(sheep), that is, empty or block head, tabula rasa; isi igho nko, as in egg head or intelligence; are epistemic.

Attempt at establishing an Igbo theory of knowledge must be dialectical of our socio-cultural environment. Human reason seeks the ultimate principles by which to make beings explainable. Already capacitated as rational, the Igbo man possesses innate ideas and intuits metaphysical principles serving as axioms. Some of these are ihe mere ede ji bee nwii (causality), ihe kwuru, ihe akwudebe ya, "relation or proportionality; ezuo ka aha eri udele, a totue ngiga, identity or community. The method takes the form of phenomenology. Phenomenology comes from the Greek phainesthai "to appear" and logos "science of. Angeles defines it as the scientific study of the essences, a science in which we come to know the mind as it is in itself, through the study of the ways in which it appears to us (210f). It is the "scientific description of consciousness and its intentional objects in their pun essences, suspending assertions for their existence, independent of consciousness" (Kelleerman, 712). As was first introduced by Johaun $\mathrm{H}$. Lambert, in his neues organon 
phenomenon was taken to mean "the illusory features of human experiences; the study became, for him the "theory of illusions." However the problem theory of knowledge bears squarely on the validity criterion, "given the illusory and imperfect nature of our sense organs and intellect. The task of validating knowledge starts by "striping away all previously acquired opinions, assumptions and prejudices not only of our everyday experience but also these interfered with our knowledge of the past. A lot of things have been written about African's past, his illogicality, irrationality, lack of philosophy and hence on absence of epistemology. Certain Igbo concepts, terms and cultural expressions cannot be adequately translated into the English language. Given the intranslatability in languages due to different conceptual schemes, Kwesi Wiredu called for deconstruction of such permissive philosophical concepts as cause, effect, such and immortality, freedom and determinism, substance, accidents, being, God, Spirits, Angels, vitalism, essence, potency, act.

The method of explanation in the natural sciences is mainly the hypothesis Deductive model. The model is "a form of logical arrangement of knowledge" in the natural sciences and encapsulates a "concrete concept of the deductive or axiomatic theory." It "applies to the specific nature of the natural science in question. Based on experiment and observation the theory presupposes the possibility of empirical verification of its propositions (Frolov, 181). The method gives rise to the experimental/analytic, the deductive or synthetic a priori methods; the third, the analytico-synthetic method is a combination of the first two. (Ryan, 16-18). The experimental/Analytic method consists in problem identification, observations, accumulation and verification of facts. For the experimentalists fact alone is of value. But sine these in themselves have neither cognitive value nor are they of necessity bound together by any principle or law possessing objective validity, the philosopher must seek the relation in realities. This is what Descartes calls the common, uniform or universal nature in all things. Philosophy is the science, which considers "first and universal or general causes". Thus a veritable method disregards the immediate causes, which the practical sciences concern themselves 
and concentrate on the ultimate reasons as underlying factors in the relations of things.

By analysis and synthesis of concepts, the Igbo epistemologist "extracts the inner core" of all realities presented to him from without, realities about the diversity in nature and as penetrated by the observer cum philosopher. Analysis is the breaking down of concepts from the complex to their simpler components. Igbo epistemology achieves this by nkowa (analysis/explanation), as in kowa ya k'odo $m$ anya; make it clear for me to understand; by debates, arguments and discussion (Iru $u k a$ ), by asking question and answering them (ajujuu na osisa) etc. We infer and deduce in accordance to the principles of formal logic and mathematics so as to disclose the order and relationship in a subject matter. To be relevant such analysis will entail cross-cultural or trans-cultural comparisons and evaluation. An Igbo epistemological explanation will derive from Igbo conceptual framework. This expresses the level of rationality, discursive climate and characteristic internal consistency of the Igbo logic of perception of reality which the whole sociocultural environment ontologically imports. Conceptual schemes differ from culture to culture; the truth as described and explained by one culture's conceptual scheme can never be adequately expressed by another. This relativism does not preclude attainment of objective truth as to imply that no truth cuts across conceptual frameworks. Contrarily, it does and this can be compared to determine its consistency with other theories.

Hermeneutic derives from the Greek hermenukos, of or for interpretation in the sense of enunciation. Referring to the Greek God Hermes hermeneutics implies "a messenger who came from the divine and hence brings the message of faith," of truth, consistency, regarding the ontological nature of things in the face of possible misinterpretation and bastardization by men in the course of their daily life. (Mchean ed., 8). This reference is suggestive of something of the exalted character of the meaning which is sought for in interpretation, in our case, the Igbo cultural values and its implication for the Igbo worldview. The message borne by Hermes is the "limitless wisdom regarding the source and hence the reality, and the value of all."(8) There is an ontological relationship and interplay between nature and man's consciousness. The values 
perceived of culture and traditions are the roots and sources of every form of knowledge of reality. On these the mind works upon and seeks to discover the unchanging and permanent guides for human action (even in a changing universe) and the "continuing structures of complex entities and the table laws of changes" (8). Therefore, hermeneutic, (as deconstructive reconstruction) is concerned, with a "vision of what is most real in itself and most lasting through time."

Aristotle was right when he indicated the concern for values in describing the philosophical quest, the science of wisdom as "knowing to what ends each thing must be done.... this end is the good of that thing, and in general the supreme good in the whole of nature." (Metaphysics, 3, 2, $\left.199^{\mathrm{b}}, 14-17\right)$. Such a science is most divine for God is the first cause and principle of all things. It will entail the promethean to unveil it. Thus Igbo people assert causal realism in Ife si na Chi, meaning that light, knowledge, wisdom, reality, or insight comes from God who has dubbed all things with his divine touch.

Human history seeks the circumstances in which one perceives the values presented in the tradition and mobilizes one's own project towards the future. Our true historical situation is understood in all truth when divested of perceptual and interpretational illusions and myopia. According to Kuhn much of what most of us accept as contemporary scientific beliefs and techniques stem from images of popular scientific accounts which are got from standard textbooks. However, what we learn of the history of science, according to W.H, Newton-Smith is "thoroughly cleaned-up versions of past scientific triumphs. We learn nothing of the failures. We glean nothing about the state of science during its barren period. And our grasp of the struggle that preceded the great moments of science derives more often than not from what the makers of these moments themselves said about the struggle (102). An indigenous science and technology, and theory of knowledge can only germinate from our true cultural history. There are shared symbolic generalizations. This implies contextually, the basic theoretical assumptions held in common by the Igbo pro-scientific community. Such assumptions on major categories of our conceptions have not been properly interpreted or are misinterpreted. Method is a disposition according to Asouzu (141). Culture predisposes, equips and capacitates for every ability. 
Every philosopher attends to problems that are current in his time. These may not be entirely new problems in the course of human history. The newness which such problem and solution tends to have is because a definite context is involved. This particularity envisages and calls for new angle or approach to the same old problem and solution; it gives a new perspective, a new interpretation, the setting of a new language, cherished values, possible reformulation (141).

Values are the basis for doing whatever we do, and holding to what we hold and defend. The values perceived by a scientific community guide and determine their agreement. Values are partly learned by the community members and they evolve with it. Values are regarded as "good-making qualities of theories and that this agreement is important in determining the particular theory choice by the scientific community" (Newton-Smith, 105). Among these values are accuracy, consistency, broad scope, simplicity and fruitfulness. Kuhn in Newton-Smith explains these five:

(i)A theory is accurate in its domain when the deduced consequences are in "demonstrated agreement with the results of existing experiments and observations"; (ii) Such a theory should be consistent not only within, itself but also with other "currently accepted theories applicable to related aspects of nature". (112); (iii) Being broad in scope means that the theories "consequences should extend beyond the particular observation, laws, or sub-theories it was initially designed to explain" (113); (iv) The simplicity brings order to phenomena that in its absence would be individually confused", and (v) A theory is fruitful if it yields new findings or discloses new phenomena or a previously un-noted relationships existing among the already known facts.

\section{Suggestions}

(i) Restructuring Academic curricula. Some decades now after the Great Debate the departments of philosophy in many of our academic institutions are yet to be properly organized and structured. Programmes of study are still shallow in others. Courses in African philosophy are yet to be introduced in some and strictly pursued in others.

(ii) Care must be taken by experts in Igbo language to properly define certain terms which are still entering contemporary discourse. 
At times Journalists arbitrarily append one concept or other to realities being discussed. Some times these do not stick. Take for instance a literal translation of "who is on the line?" as onye no/kwu na udo? Placing some emphasis on the use of local dialects and languages by students and academics, beyond what is presently obtainable, will go a long to enhancing proficiency in translation and interpretations.

(iii) It might be helpful making our conference and seminars look more of a workshop, to focus more on technicality.

(iv) Institutions should encourage professionalism in relevant and core areas of the discipline. Promotions and incentives should be given, study opportunities put in place. 


\section{References}

Alan J. Mortimer, ed., The Great Ideas ,A Syntopicon of Great Books of the Western World,Vol.,11,Chicago: Encyclopaedia Britannica,Inc., 1952.

Agbakoba J.C.A., Philosophy and Development: Metatheoretical and Methodological Considerations in Uche, the Journal of the Department of philosophy, vol.11,2005.

Alwin, Diemer,ed.,Philosophy in Present Situation of Afirca, Symposium....,Wiesbalden, German:Franz Steiner Velag GMBH-, 1981

Angeles Petered., Dictionary of Philosophy, London: Harper and Row Publishers, 1881

Aristotle, Metaphysics in Basic Works of Aristotle, edt. by W. D. Ross, New York: Random House, Inc., 1941

Asouzu I. Innocent, Ikwa Ogwe, Essential Readings in Contemporary Reflection Systematic Methodological Approach, Calabar: Saesprint, Publishers, 2007

Rene Descartes, A Discourse on Method ,trans. by Veitch J., London: Everyman's Library, 1912

Eboh, Ben O., Basic Issues In the Theories of Knowledge, Nsukka Fulladu Publishig, 1995

Frolov ed., Dictionary of Philosophy, Moscow :Progress Publishers, 1981

Hamlyn D.W., Theory of Knowledge, 1st edn., London: The Macmillan Press Ltd.,1970

Kellerman D., The Lexicon Webster Dictionary, Vol.,1,USA

McLean, George F., ed. Hermeneutics, Faith and Relation Between

Cultures,Vol.17,USA: The Council For the Research in value and Philosophy, 1972

Newton-Smith, W. H., The Rationality of Science, Boston,: Routledge and Kegan Paul Ltd, 1981 